\section{RMD Open}

Rheumatic \&

Musculoskeletal Diseases

\title{
Hospitalisation rates among patients with primary Sjögren's syndrome: a population-based study, 1995-2016
}

\author{
Gabriel Maciel, ${ }^{1,2}$ Luisa Servioli, ${ }^{1,2}$ Carlotta Nannini, ${ }^{1,3}$ Alvise Berti, ${ }^{4,5}$ \\ Cynthia S Crowson, ${ }^{1,6}$ Sara J Achenbach, ${ }^{6}$ Eric L Matteson, ${ }^{1,7}$ Divi Cornec ${ }^{4,8}$
}

To cite: Maciel G, Servioli L, Nannini C, et al. Hospitalisation rates among patients with primary Sjögren's syndrome: a population-based study, 1995-2016. RMD Open 2018;4:e000575. doi:10.1136/ rmdopen-2017-000575

- Prepublication history and additional material for this paper are available online. To view these files, please visit the journal online(http://dx.doi org/10.1136/rmdopen-2017000575).

Received 11 September 2017 Revised 29 December 2017 Accepted 8 February 2018

\section{ABSTRACT}

Objective To determine rates and primary discharge diagnoses of hospitalisation in a cohort of patients with incident primary Sjögren's syndrome (pSS) compared with the general population.

Methods This was a retrospective population-based cohort study focused on Olmsted County, Minnesota. The pSS cohort consisted of patients with incident pSS in the 1976-2015 period and was compared with a cohort of individuals without pSS matched 3:1 for age, sex and calendar year, randomly selected from the same population. Hospitalisations in 1995-2016 were examined. Discharge diagnoses were categorised using the Clinical Classifications Software for International Classification of Diseases, 9th revision, Clinical Modification.

Results A total of 385 hospitalisations occurred in the 160 patients with pSS during 1592 person-years of follow-up. Among 466 comparators, there were 899 hospitalisations during 4660 person-years of follow-up, resulting in a significantly higher rate of hospitalisations in patients with pSS (rate ratio (RR): $1.25,95 \% \mathrm{Cl}: 1.11$ to 1.41 ). Rates of hospitalisation were increased among patients with pSS for endocrine, nutritional and metabolic diseases and immunity disorders (RR $1.82,95 \% \mathrm{Cl} 1.08$ to 2.98), diseases of the musculoskeletal system and connective tissue (RR 1.49, 95\% $\mathrm{Cl} 1.05$ to 2.05) and for injuries and poisoning (RR 1.46, 95\% $\mathrm{Cl} 1.01$ to 2.06). While not significantly increased overall, hospitalisations for diseases of the circulatory system were significantly increased in patients with pSS aged $\geq 75$ years (RR $1.54,95 \% \mathrm{Cl} 1.11$ to 2.11).

Conclusions Patients with pSS experienced higher rates of hospitalisation than the general population. Hospitalisations for endocrine/metabolic disorders, diseases of the circulatory system, diseases of the musculoskeletal system and connective tissue disorders, and injuries were more common among patients with pSS than comparators.

\section{INTRODUCTION}

Primary Sjögren's syndrome (pSS) is a multisystem autoimmune disease characterised by an inflammatory infiltrate and progressive dysfunction of exocrine glands, especially the lachrymal and salivary glands. ${ }^{1}$ Estimates of the frequency of pSS vary worldwide. ${ }^{2} \mathrm{~A}$

\section{Key messages}

What is already known about this subject?

- Patients with primary Sjögren's syndrome have a decreased quality of life, but little is known about the other public health-related aspects of the disease, including health care system utilisation.

What does this study add?

- Patients with pSS experience higher rates of hospitalisation than the general population.

- The increased risk for hospitalisation was highest in the first 4 years after pSS diagnosis.

- The increased risks for hospitalisation were primarily due to endocrine/metabolic and musculoskeletal/connective tissue disorders.

How might this impact on clinical practice?

- Better knowledge of the burden of the disease is of paramount importance for public stakeholders when making a decision concerning the disease.

recent study from this group reported that the 2015 prevalence of pSS in Olmsted County, Minnesota, was 103 per 100000 inhabitants by physician diagnosis but only 22 per 100000 according to classification criteria. ${ }^{3}$ The annual incidence in this population from 1976 to 2015 was 5.8 per 100000 inhabitants with a significant progressive increase in more recent years. ${ }^{4}$

The most common manifestations of pSS are oral and ocular dryness. ${ }^{56} \mathrm{Up}$ to one-third of patients can experience extraglandular involvement including polysynovitis, vasculitis, neurological compromise and inflammatory lung and renal disease. ${ }^{7-10}$ pSS may be associated with malignancies, especially non-Hodgkin lymphoma, ${ }^{11}$ and patients are at higher risk for cardiovascular disease. ${ }^{12}$ Disease-related complications and comorbidities may lead to hospitalisation and contribute to increased healthcare costs and decreased quality of life for these patients. ${ }^{13}$ However, 
little is known about the hospitalisation rate and risk factors in pSS. ${ }^{15}$ Knowledge of hospitalisation rates and risks could help to identify the patients at higher risk of hospitalisation and reflect the economic burden of the disease. The objective of this study was to determine the rates and primary discharge diagnoses of hospitalisation in a population-based cohort of patients with incident pSS relative to matched comparators randomly selected from the same background population.

\section{METHODS}

\section{Cases and comparators}

This study utilised a previously identified cohort of patients with incident physician-diagnosed pSS among Olmsted County, Minnesota residents in 1976-2015. Each of the cases was matched to three comparators randomly selected from Olmsted County residents of the same age and sex without pSS and indexed to the date of pSS diagnosis.

This population is well suited for investigation of the epidemiology of pSS because of the availability of comprehensive medical record information for the entire population. ${ }^{16} 17$ The information was extracted using the resources of the Research Epidemiology Project (REP). This is a medical records linkage system that allows ready access to complete (inpatient and outpatient) records from all healthcare providers from the local population, including Mayo Clinic, Olmsted Medical Center and their affiliated hospitals, local nursing homes and a few private practitioners. ${ }^{18}$ This system ensures complete clinical information on all clinically recognised cases of pSS in Olmsted County residents.

\section{Hospitalisations and discharge diagnoses}

Hospitalisations in 1995-2016 were examined. Patients without follow-up after 1 January 1995 were excluded from both cohorts. Patients in both cohorts were followed until death, migration from Olmsted County or 31 December 2016. Collected data included admission and discharge dates for all hospitalisations. Primary discharge diagnoses were categorised using the Clinical Classifications Software (CCS) for International Classification of Diseases, 9th revision, Clinical Modification, from the Healthcare Cost and Utilization Project (www. hcup-us.ahrq.gov/toolssoftware/ccs/ccs.jsp.) The CCS groups diagnoses into 18 mutually exclusive chapters: infection and parasitic diseases; neoplasms; endocrine, nutritional and metabolic diseases and immunity disorders (referred to a 'endocrine/metabolic' hereafter); diseases of the blood and blood forming organs; mental illness; diseases of the nervous system and sense organs; diseases of the circulatory system; diseases of the respiratory system; diseases of the digestive system; diseases of the genitourinary system; complications of pregnancy; childbirths and puerperium; diseases of the skin and subcutaneous tissue; diseases of musculoskeletal system and connective tissue; congenital anomalies; certain conditions originating in the perinatal period; injury and poisonings (which include fractures); symptoms, signs and ill-defined conditions; residual codes; and unclassified. Readmission rates were defined as a hospital admission date within 30 days of a prior discharge date.

\section{STATISTICAL ANALYSES}

Descriptive statistics (mean, percentages and so on) were used to summarise the data. Data were analysed using person-year methods and rate ratios (RRs) comparing pSS cases to comparators. Comparisons of person-year rates were performed using Poisson methods. Poisson regression models with smoothing splines were used to examine trends over time to allow for non-linear effects. Comparisons of length of stay for pSS cases versus comparators were performed using generalised linear models adjusted for age, sex and calendar year with random intercepts to account for multiple hospitalisations in the same patient. Readmission rates were calculated as the number of readmissions divided by the number of subsequent hospitalisations (not counting the first hospitalisation for each patient, as it could not be a readmission by definition). Analyses were performed using SAS V.9.4 and R V.3.2.3 (R Foundation for Statistical Computing, Vienna, Austria).

\section{RESULTS}

The cohorts included 171 patients with physician-diagnosed pSS and 513 comparators. Detailed description of the incident pSS cohort has been previously published. ${ }^{4}$ After exclusion of patients without follow-up after 1 January 1995, the analysis included 160 patients with pSS and 466 comparators. Among the 160 patients with pSS, 140 (88\%) were women, the mean \pm SD age at baseline date was $60.2 \pm 16.5$ years and the median (IQR) length of follow-up was 9.9 (4.0-14.3) years. Disease features of the pSS patients are detailed in online supplementary table 1 . Among patients with available results $(\mathrm{n}=130)$, anti-Ro/ SSA antibodies were present in 74\%. Labial salivary gland biopsy was performed in 21 patients (positive in 12). The American-European Consensus Group classification criteria were ascertainable and fulfilled in only $19 \%$ of the patients, because some tests included in the criteria were performed in a small number of patients (objective eye and mouth dryness evaluation and lip biopsy). There were 385 hospitalisations in patients with pSS during a total of 1592 person-years of follow-up (hospitalisation rate: 24.2 per 100 person-years), the majority of which occurred among those $\geq 75$ years old $(n=192)$. Among the 466 comparators (mean \pm SD age: $59.6 \pm 16.2$ years; $87 \%$ women; median (IQR) follow-up: 9.6 (3.8-14.5 years)), there were 899 hospitalisations during a total of 4660 person-years of follow-up (hospitalisation rate: 19.3 per 100 person-years), resulting in a statistically significant higher rate of hospitalisations in patients with pSS (RR $1.25,95 \%$ CI 1.11 to 1.41$)$. 
Unadjusted rates of hospitalisation according to age, sex, calendar year and disease duration are shown in table 1. Hospitalisation rates increased with age in both cohorts. Overall hospitalisation rates were increased by twofold among patients with pSS aged 17-49 years relative to comparators (RR 2.02; 95\% CI 1.40 to 2.87), by $30 \%$ among patients with pSS aged $\geq 75$ years (RR 1.30 ; $95 \%$ CI 1.10 to 1.54 ), but not among the middle-aged patients. Hospitalisation rates were similar between men and women in patients with pSS and comparators $(\mathrm{P}=0.98$ and $\mathrm{P}=0.10$, respectively). Women with $\mathrm{pSS}$ had a $23 \%$ increased risk of hospitalisation relative to women comparators (RR 1.23; 95\% CI 1.08 to 1.39 ). Men with pSS had a $64 \%$ increased risk of hospitalisation relative to comparators (RR 1.64; 95\% CI 1.06 to 2.49). Age and sex adjusted trends in hospitalisation rates over calendar time among patients with $\mathrm{pSS}$ and comparators remained stable over time $(\mathrm{P}=0.80$ and $\mathrm{P}=0.32$, respectively). The unadjusted hospitalisation rates among patients with pSS were consistent in the first 4 years and subsequently (table 1). In contrast, the hospitalisation rates increased over follow-up time in the comparators. Therefore, differences in hospitalisation rates in patients with pSS relative to comparators were greatest in the first 4 years after index date and progressively decreased thereafter. When the rates were adjusted for sex, age and calendar year, we observed a slight decline in hospitalisation rates among patients with pSS over disease duration with a steady rate of hospitalisations among the comparators (figure 1). We found no evidence that the increased rate of hospitalisations in patients with pSS was due to a small number of patients with multiple admissions. The RRs for the first five hospitalisations and for $>5$ hospitalisations were similar to the overall RR (data not shown).

The most frequent primary discharge diagnosis categories for hospitalisation in patients with pSS were diseases of the circulatory system $(\mathrm{n}=74)$, diseases of the musculoskeletal system and connective tissue $(n=52)$, injuries and poisoning $(\mathrm{n}=45)$ and diseases of respiratory system $(\mathrm{n}=39$; table 2$)$. Compared with controls without pSS, rates of hospitalisation were increased among patients with pSS for endocrine/metabolic diseases (RR 1.82, $95 \%$ CI 1.08 to 2.98), diseases of the musculoskeletal system and connective tissue (RR 1.49, 95\% CI 1.05 to 2.05 , after exclusion of sicca syndrome for comparability) and injuries and poisoning (RR 1.46, 95\% CI 1.01 to 2.06). There were no statistically significant differences in the remaining hospitalisation discharge diagnosis categories between the two cohorts.

Within the discharge diagnosis categories that were associated with increased risks, subcategories of diagnoses were examined to determine which diagnoses were driving the increases. In the endocrine/metabolic category, fluid and electrolyte disorders were more common in patients with pSS than comparators. For the musculoskeletal disease category, the subcategory including spondylosis, intervertebral disc disorders and other back problems was more common in patients with pSS than comparators. In the injury category, complications of device, implant or graft were more common in pSS than comparators.

Among the young (ages 17-49 years), hospitalisations were increased in the neoplasms (RR 3.32; 95\% CI 1.14, 10.15), mental illness (RR 7.00; 95\% CI 2.22 to 31.62) with leukaemia and lymphoma the most common neoplasms and depression the most common mental illness. For those aged $\geq 75$ years, hospitalisations were significantly increased in patients with pSS relative to comparators in the diseases of the circulatory system (RR $1.54,95 \% \mathrm{CI}$ 1.11 to 2.11 ), the respiratory system (RR $1.75 ; 95 \%$ CI 1.09 to 2.72) and in the endocrine/metabolic category (RR 2.80; 95\% CI 1.23 to 6.32) with heart failure, respiratory failure and fluid/electrolyte disorders more common among patients with pSS than comparators.

The average length of stay was 3.9 days (median=3; IQR 2-5 days) for patients with pSS and 4.7 days (median=3; IQR 2-5 days) for comparator subjects $(\mathrm{P}=0.08)$. Readmission rates among patients with pSS were not different from non-pSS comparators; 52 readmissions in pSS accounting for $18 \%$ of 284 subsequent hospitalisations and 122 readmissions in non-pSS subjects accounting for $19 \%$ of 656 subsequent hospitalisations $(\mathrm{P}=0.92)$.

\section{DISCUSSION}

This study demonstrated that patients with pSS undergo hospitalisation at a higher rate than persons without pSS. The increased rate was found in both sexes and in ages $<50$ and $\geq 75$ years, with the highest $R R$ in the first 4 years after index date, which progressively decreased thereafter. The most common diagnoses associated with hospitalisation in both cohorts were diseases of the circulatory system, especially congestive heart failure and disease of the musculoskeletal system, especially degenerative spine disorders.

There are few studies of hospitalisation for patients with pSS. Better description of rates and causes of hospitalisation in these patients is important for healthcare providers, insurers, public stakeholders, regulatory agencies and drug companies. A retrospective study from Mexico in 2015 reported that the main causes of hospitalisation among patients with pSS were disease activity and infections. ${ }^{19}$ In the current study, disease activity could not be adequately assessed because of lack of standard reporting by physicians. In contrast to the study from Mexico, rates of hospitalisation due to infections were not increased.

In general, hospitalisation rates are higher in patients with rheumatic diseases than in the general population. Active disease and infections are leading causes of hospitalisation in systemic lupus erythematosus. ${ }^{20-24}$ Analysis of a retrospective cohort of patients with rheumatoid arthritis, psoriasis arthritis and spondyloarthropathy treated with antitumour necrosis factor alpha agents found a significant decrease in hospitalisations due to flares of rheumatic diseases when compared with the 


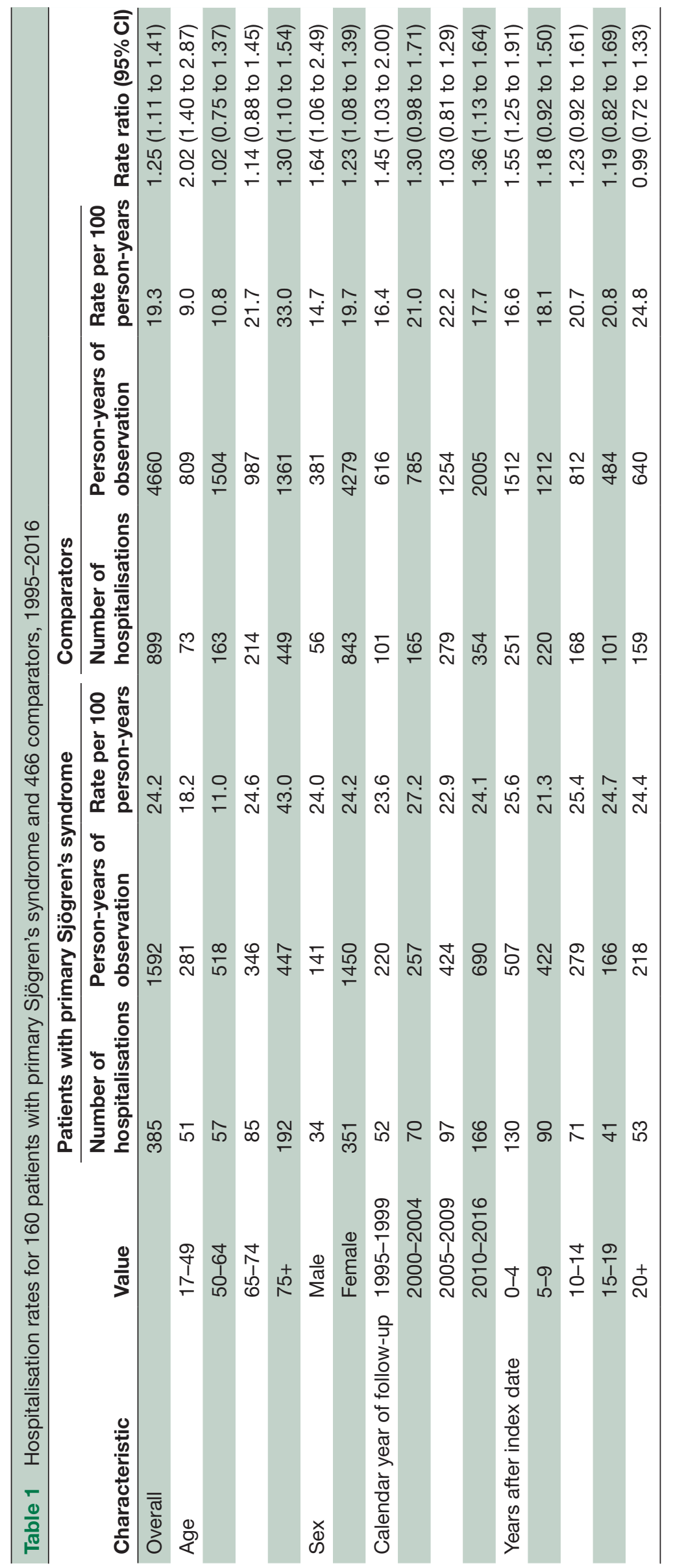




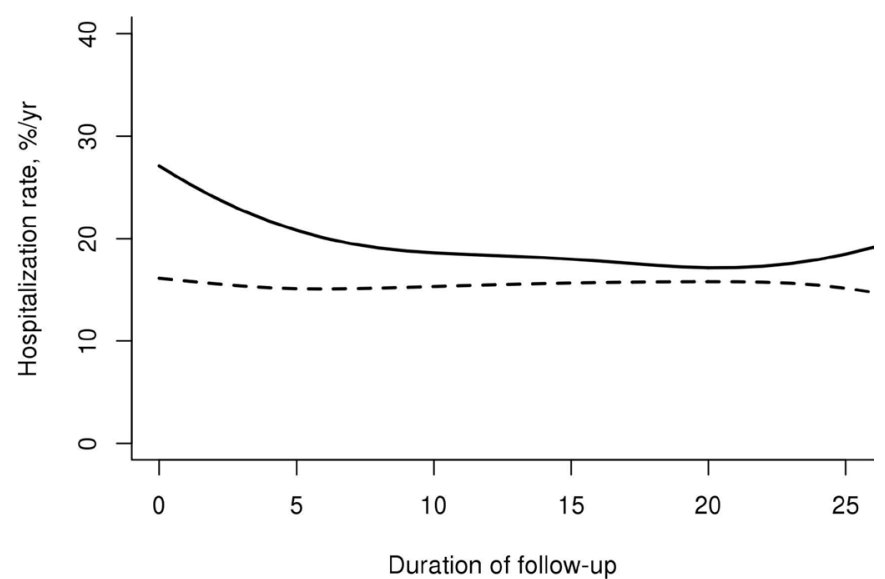

Figure 1 Hospitalisation rate of patients with primary Sjögren syndrome (solid line) and comparators (dashed line) according to duration of follow-up, adjusted for age, sex and calendar year.

prebiological treatment era, but an increase of infection events was observed in the biological group. ${ }^{25} \mathrm{~A}$ recent population-based study of hospitalisation in patients with RA from Olmsted County reported increased hospitalisation rates in 10 disease categories (ie, infections/parasitic, endocrine/metabolic, blood/blood forming organs, circulatory system, respiratory system, digestive system, genitourinary system, skin/subcutaneous system, musculoskeletal/connective tissue and injuring/poisoning). ${ }^{26}$ Among patients with scleroderma, the main indications for hospitalisations were infections followed by pulmonary hypertension. ${ }^{27}$

The average length of hospital stay was similar among patients with pSS and non-pSS comparators, while other authors report a longer length of hospitalisation for pSS patients (median 9 days; IQR $6-15$ days). ${ }^{19}$ Readmission rates were similar among both groups.

Strengths of the current study include the use of a well-characterised population-based cohort of patients with incident pSS and a cohort of comparators without pSS randomly selected from the same background population. The comprehensive resources of the REP allowed complete ascertainment of hospitalisations from all healthcare providers in Olmsted County.

The principal limitation of the study is the retrospective nature of the data collection, with a potential risk of underestimation of hospitalisations if patients were hospitalised outside Olmsted County. The definition of pSS cases according to the physician diagnosis in this cohort is an important point to consider. The definition, diagnosis and classification of systemic autoimmune diseases are complex issues, especially concerning pSS, and

Table 2 Hospitalisation rates for 160 patients with primary Sjögren syndrome and 466 comparators according to categorised primary discharge diagnoses, 1995-2016

\begin{tabular}{|c|c|c|c|c|c|}
\hline \multirow[b]{2}{*}{ Diagnosis category* } & \multicolumn{2}{|c|}{$\begin{array}{l}\text { Patients with primary Sjögren's } \\
\text { syndrome } \\
\text { (n=160; person-years=1592) }\end{array}$} & \multicolumn{2}{|c|}{$\begin{array}{l}\text { Comparators } \\
(n=466 ; \text { person-years }=4660)\end{array}$} & \multirow[b]{2}{*}{ Rate ratio $(95 \% \mathrm{CII})$} \\
\hline & $\begin{array}{l}\text { Number of } \\
\text { hospitalisations }\end{array}$ & $\begin{array}{l}\text { Rate per } 100 \\
\text { person-years }\end{array}$ & $\begin{array}{l}\text { Number of } \\
\text { hospitalisations }\end{array}$ & $\begin{array}{l}\text { Rate per } 100 \\
\text { person-years }\end{array}$ & \\
\hline Overall & 385 & 24.2 & 899 & 19.3 & 1.25 (1.11 to 1.41$)$ \\
\hline Infectious and parasitic diseases & 12 & 0.8 & 30 & 0.6 & 1.20 (0.59 to 2.24$)$ \\
\hline Neoplasms & 18 & 1.1 & 45 & 1.0 & 1.19 (0.67 to 1.99$)$ \\
\hline $\begin{array}{l}\text { Endocrine, nutritional and metabolic } \\
\text { diseases and immunity disorders }\end{array}$ & 24 & 1.5 & 39 & 0.8 & $1.82(1.08$ to 2.98$)$ \\
\hline Mental illness & 13 & 0.8 & 31 & 0.7 & 1.25 (0.63 to 2.30$)$ \\
\hline $\begin{array}{l}\text { Diseases of the nervous system and sense } \\
\text { organs }\end{array}$ & 14 & 0.9 & 33 & 0.7 & 1.27 (0.65 to 2.28$)$ \\
\hline Diseases of the circulatory system & 74 & 4.7 & 186 & 4.0 & 1.17 (0.89 to 1.52$)$ \\
\hline Diseases of the respiratory system & 39 & 2.5 & 89 & 1.9 & 1.29 (0.87 to 1.86$)$ \\
\hline Diseases of the digestive system & 28 & 1.8 & 94 & 2.0 & 0.88 (0.57 to 1.31$)$ \\
\hline Diseases of the genitourinary system & 22 & 1.4 & 61 & 1.3 & 1.07 (0.64 to 1.70$)$ \\
\hline $\begin{array}{l}\text { Complications of pregnancy; childbirth and } \\
\text { the puerperium }\end{array}$ & 9 & 0.6 & 20 & 0.4 & 1.36 (0.58 to 2.82$)$ \\
\hline $\begin{array}{l}\text { Diseases of the skin and subcutaneous } \\
\text { tissue }\end{array}$ & 7 & 0.4 & 17 & 0.4 & 1.25 (0.48 to 2.80$)$ \\
\hline Connective tissue $\dagger$ & 52 & 3.3 & 103 & 2.2 & 1.49 (1.05 to 2.05$)$ \\
\hline Injury and poisoning & 45 & 2.8 & 91 & 2.0 & $1.46(1.01$ to 2.06$)$ \\
\hline Symptoms, signs and ill-defined conditions & 20 & 1.3 & 42 & 0.9 & 1.41 (0.81 to 2.35$)$ \\
\hline
\end{tabular}

*The following four categories with $<5$ hospitalisation in patients with primary Sjögren syndrome were excluded: diseases of the blood and blood-forming organs, congenital anomalies, certain conditions originating in the perinatal period, residual codes and unclassified. †Two hospitalisations for Sicca syndrome were removed from diseases of the musculoskeletal system and connective tissue for comparability. 
must be viewed in the context they are used. Classification criteria are tools developed specifically for research purposes and not for diagnosing patients in clinical practice. In the setting of a referral centre dedicated to the disease, a patient with suspected pSS will likely undergo more comprehensive evaluation and diagnostic testing, including invasive procedures that aid for example in establishing whether the patient fulfils specific disease classification criteria and could be included in a clinical trial.

In this observational study, the approach is necessarily different. Patients who received a diagnosis of pSS in clinical routine practice in the community setting of Olmsted County were included. Clinical elements that lead to the physician diagnosis were captured. This is the only way of studying the disease in a 'real life' situation, that is, outside the setting of a research centre dedicated to the disease, where actually only a small fraction of patients with pSS are diagnosed and treated. The approach taken in this study reflects the actual number of patients who are diagnosed with the disease in clinical practice. It is evident that, in clinical practice, physicians rarely use some tests that have nonetheless important clinical value, such as salivary gland biopsy, probably because they consider that test results would not influence their clinical decisions. Physicians indeed do not use these classification criteria to diagnose the disease in their patients in the community setting and in general order invasive tests only if they are convinced that their results would change their clinical decisions. There is no 'gold standard' to define a complex disease such as pSS, and we believe that only the analysis of physician-diagnosed cases can represent the real burden of the disease in our society. ${ }^{28} 29$

We cannot rule out that the increased hospitalisation rate that we observed in patients with pSS could be explained by some comorbidities rather that by the disease itself. However, each patient with incident pSS was individually matched with three residents from the same well-defined geographic area, according to age, sex and index year. Therefore, differences between cases and comparators should be exclusively explained by the disease itself or by comorbidities strongly related to the disease. Our present analysis was based on an electronic retrieval of discharge diagnoses, and we do not have further data on comorbidities at diagnosis or during follow-up. This important question will require further chart review and manual data extraction.

In conclusion, patients with pSS experience higher rates of hospitalisation than the general population. This is true for both sexes, and in the young (ages 17-49 years) and the old (ages $\geq 75$ years), but not the middleaged. The increased risk for hospitalisation was highest in the first 4 years after pSS diagnosis and declined thereafter. The most common causes for hospitalisation were diseases of the circulatory system and diseases of the musculoskeletal/connective tissue disorders in both patients with and without pSS, but the increased risks for hospitalisation among patients with pSS were primarily due to endocrine/metabolic and musculoskeletal/ connective tissue disorders. Further studies are needed to identify patients at particular risk for hospitalisation and address ways to prevent hospitalisation as well as to define its economic burden.

Author affiliations

${ }^{1}$ Division of Rheumatology, Mayo Clinic College of Medicine and Science, Rochester, Minnesota, USA

${ }^{2}$ Office for Autoimmune Diseases, Medical Clinic 1, Hospital Maciel, Montevideo, Uruguay

${ }^{3}$ Department of Rheumatology, Hospital of Prato, Prato, Italy

${ }^{4}$ Division of Pulmonary and Critical Care Medicine, Mayo Clinic College of Medicine and Science, Rochester, Minnesota, USA

${ }^{5}$ Immunology, Rheumatology, Allergy and Rare Diseases Department, San Raffaele Scientific Institute, Milan, Italy

${ }^{6}$ Division of Biomedical Statistics and Informatics, Department of Health Sciences Research, Mayo Clinic College of Medicine and Science, Rochester, Minnesota, USA

${ }^{7}$ Division of Epidemiology, Department of Health Sciences Research, Mayo Clinic College of Medicine and Science, Rochester, Minnesota, USA

${ }^{8}$ INSERM UMR1227, Lymphocytes B et Autoimmunité, Université de Bretagne Occidentale, Rhumatologie, CHU de Brest, Brest, France

Contributors CSC, ELM and DC designed the study. GM, LS, CN and AB retrieved the data. CSC and SJA performed the statistical analysis. GM, CSC, ELM and DC drafted the manuscript. All authors read and approved the final version for submission.

Funding This work was made possible using the resources of the Rochester Epidemiology Project, which is supported by the National Institute on Aging of the National Institutes of Health under Award Number R01AG034676 and CTSA Grant Number UL1 TR000135 from the National Center for Advancing Translational Sciences (NCATS), a component of the National Institutes of Health (NIH). DC received a grant from the French Society of Rheumatology (SFR) and from Brest University Hospital for his current fellowship at Mayo Clinic.

Disclaimer The content is solely the responsibility of the authors and does not necessarily represent the official views of the National Institutes of Health.

Competing interests None declared.

Patient consent Obtained.

Ethics approval Mayo Clinic IRB.

Provenance and peer review Not commissioned; externally peer reviewed.

Open Access This is an Open Access article distributed in accordance with the Creative Commons Attribution Non Commercial (CC BY-NC 4.0) license, which permits others to distribute, remix, adapt, build upon this work non-commercially, and license their derivative works on different terms, provided the original work is properly cited and the use is non-commercial. See: http://creativecommons.org/ licenses/by-nc/4.0/

(c) Article author(s) (or their employer(s) unless otherwise stated in the text of the article) 2018. All rights reserved. No commercial use is permitted unless otherwise expressly granted.

\section{REFERENCES}

1. Brito-Zerón P, Baldini C, Bootsma $\mathrm{H}$, et al. Sjögren syndrome. Nat Rev Dis Primers 2016;2:16047.

2. Cornec $D$, Chiche $L$. Is primary Sjögren's syndrome an orphan disease? A critical appraisal of prevalence studies in Europe. Ann Rheum Dis 2015;74:e25.

3. Maciel G, Crowson CS, Matteson EL, et al. Prevalence of primary Sjögren's syndrome in a US Population-based cohort. Arthritis Care Res 2017;69:1612-6.

4. Maciel G, Crowson CS, Matteson EL, et al. Incidence and mortality of physician-diagnosed primary sjögren syndrome: time trends over a 40-year period in a population-based US cohort. Mayo Clin Proc 2017;92:734-43.

5. Cornec D, Saraux A, Jousse-Joulin S, et al. The differential diagnosis of dry eyes, dry mouth, and parotidomegaly: a comprehensive review. Clin Rev Allergy Immunol 2015;49:278-87. 
6. Le Gall M, Cornec D, Pers JO, et al. A prospective evaluation of dental and periodontal status in patients with suspected Sjögren's syndrome. Joint Bone Spine 2016;83.

7. Malladi AS, Sack KE, Shiboski SC, et al. Primary Sjögren's syndrome as a systemic disease: a study of participants enrolled in an international Sjögren's syndrome registry. Arthritis Care Res 2012;64:911-8.

8. Carvajal Alegria G, Guellec D, Mariette X, et al. Epidemiology of neurological manifestations in Sjögren's syndrome: data from the French ASSESS Cohort. RMD Open 2016;2:e000179.

9. Lechtman S, Debray MP, Crestani B, et al. Cystic lung disease in Sjögren's syndrome: An observational study. Joint Bone Spine 2017;84:317-21.

10. Darrieutort-Laffite C, André V, Hayem G, et al. Sjögren's syndrome complicated by interstitial cystitis: A case series and literature review. Joint Bone Spine 2015;82:245-50.

11. Nocturne G, Virone A, Ng WF, Wf N, et al. Rheumatoid factor and disease activity are independent predictors of lymphoma in primary Sjögren's syndrome. Arthritis Rheumatol 2016;68:977-85.

12. Bartoloni E, Baldini C, Schillaci G, et al. Cardiovascular disease risk burden in primary Sjögren's syndrome: results of a population-based multicentre cohort study. J Intern Med 2015;278:185-92.

13. Cornec D, Devauchelle-Pensec V, Mariette X, et al. Severe healthrelated quality of life impairment in active primary Sjögren's syndrome and patient-reported outcomes: data from a large therapeutic trial. Arthritis Care Res 2017;69:528-535.

14. Milin $M$, Cornec D, Chastaing $M$, et al. Sicca symptoms are associated with similar fatigue, anxiety, depression, and qualityof-life impairments in patients with and without primary Sjögren's syndrome. Joint Bone Spine 2016;83:681-5.

15. Callaghan R, Prabu A, Allan RB, et al. Direct healthcare costs and predictors of costs in patients with primary Sjogren's syndrome. Rheumatology 2007;46:105-11.

16. St Sauver JL, Grossardt BR, Yawn BP, et al. Use of a medical records linkage system to enumerate a dynamic population over time: the Rochester epidemiology project. Am J Epidemiol 2011;173:1059-68.

17. Rocca WA, Yawn BP, St Sauver JL, et al. History of the Rochester epidemiology project: half a century of medical records linkage in a US population. Mayo Clin Proc 2012;87:1202-13.
18. St Sauver JL, Grossardt BR, Leibson CL, et al. Generalizability of epidemiological findings and public health decisions: an illustration from the Rochester Epidemiology Project. Mayo Clin Proc 2012;87:151-60.

19. Atisha-Fregoso $\mathrm{Y}$, Rivera-Vicencio $\mathrm{Y}$, Baños-Pelaez $\mathrm{M}$, et al. Main causes and risk factors for hospitalisation in patients with primary Sjögren's syndrome. Clin Exp Rheumatol 2015;33:721-5.

20. Edwards $\mathrm{CJ}$, Lian TY, Badsha $\mathrm{H}$, et al. Hospitalization of individuals with systemic lupus erythematosus: characteristics and predictors of outcome. Lupus 2003;12:672-6.

21. Lee J, Dhillon N, Pope J. All-cause hospitalizations in systemic lupus erythematosus from a large Canadian referral centre. Rheumatology 2013;52:905-9.

22. Petri M, Genovese M. Incidence of and risk factors for hospitalizations in systemic lupus erythematosus: a prospective study of the Hopkins Lupus Cohort. J Rheumatol 1992;19:1559-65.

23. Teh CL, Wong JS, Ngeh NK, et al. Systemic lupus erythematosus pregnancies: a case series from a tertiary, East Malaysian hospital. Lupus 2009;18:278-82.

24. Thorburn CM, Ward MM. Hospitalizations for coronary artery disease among patients with systemic lupus erythematosus. Arthritis Rheum 2003;48:2519-23.

25. Zisman D, Haddad A, Hashoul S, et al. Hospitalizations of patients treated with anti-tumor necrosis factor- $\alpha$ agents -- a retrospective cohort analysis. J Rheumatol 2013;40:16-22.

26. Michet CJ, Strobova K, Achenbach S, et al. Hospitalization rates and utilization among patients with rheumatoid arthritis: a populationbased study from 1987 to 2012 in Olmsted County, Minnesota. Mayo Clin Proc 2015;90:176-83.

27. Netwijitpan S, Foocharoen C, Mahakkanukrauh A, et al. Indications for hospitalization and in-hospital mortality in Thai systemic sclerosis. Clin Rheumatol 2013;32:361-7.

28. Nocturne G, Seror R, Devauchelle-Pensec V, et al. Prevalence of primary Sjögren syndrome: what if Sjögren was right after all? Arthritis Care Res 2017.

29. Maciel G, Crowson CS, Matteson EL, et al. Prevalence of primary Sjögren's syndrome: Sjögren may have indeed been right. Arthritis Care Res 2017 